\title{
THREATS AND RISKS TO EUROPEAN UNION SECURITY RELATED TO MIGRATION
}

DOI: http://dx.doi.org/10.18509/GBP.2019.43

UDC: 314.15(4-672EY)

\author{
Nikolay Katsarski \\ Sofia University “St. Kliment Ohridski”, Faculty of Geology and Geography, \\ Department of Regional Development, Bulgaria
}

\begin{abstract}
More and more people are living in the European Union beyond its borders. Some of them are looking for a better future. Others are chased by military action, political persecution, or natural disaster. The increasing migratory pressure creates a need to redirect significant financial and organizational resources to address the situation. The lack of prospect of lasting stability in the source countries determines the continuation of this trend, with limited capacity of institutions to secure the processes. In this regard, the expected increase in migrants in our territory creates direct risks for a humanitarian crisis. Regarding legal immigration, at a political level, Europe can speak of a generally positive attitude, leading also to a number of concrete initiatives. There are laws that allow immigrants, after working for at least a year, to come together with their families. Persons who have been legally resident for five years in the EU may be granted a long-stay permit, which allows them to pass on a higher level of qualification or to work in another Member State of the Union. Due to the economic crisis, the situation of immigrants in Europe at this time is particularly difficult. One of the most frequent reasons for immigration is the demand for employment, but as employers usually dismiss first employees and workers, the most severe consequences of the economic downturn are felt by immigrants, especially in the countries hardest hit by the crisis.
\end{abstract}

Keywords: migration, economic crisis, migrants

\section{INTRODUCTION}

Migrations have played a very important role in the development of Mankind. Their main function has always been to ensure people's mobility and effective territorial disposition in terms of their ability to live and work. Migrations have also contributed to the rational use of labor, human and natural resources in a given territory. Migrations are often associated with improving the educational and qualification structure of the population, increasing its cultural level, but also with the increase in its needs and the expansion of the domestic and foreign markets [2].

More and more people are living in the European Union beyond its borders. Some of them are looking for a better future. Others are chased by military action, political persecution, or natural disaster. This makes the theme of "migrants" a leader in the political agenda of many Member States. On the scale of the problem and the challenges it poses to the EU Member States, there are numerous testimonies to which I will draw attention in the next chapters of this paper. The situation of economies existing in post-crisis environment, the lack of well-developed policies, the shock of admission of the foreigner, the large size of immigration flows, whether they are migrant job seekers, refugees or asylum seekers, pose a threat to the security of the Union and the national security of our country. 


\section{MATERIALS AND METHODS}

The current study of migration, is based on 6 basic principles: realism - realistic goals must be formulated in threats and risks to european union security related to migration; comprehensiveness - In the case of migration planning and security, consultations must be national, sectoral and regional; sustainability - migration dicisions should not include tasks, events and specific activities, the solving of which has an isolated campaign character, with a short-term and rapid "dulling" over time effect on the implementation of the formulated goals in the strategy; transparency - All strategic documents of government / local government and all opinions expressed by participants in the planning process should be publicly available; continuity - security planning should not start "from scratch" - continuity with the planning of the territory as a whole must be ensured; to have a connection with the other strategic documents in the respective territory; partnership and equality - Strategic planning for migration security should be the result of joint efforts of many stakeholders (representatives of state and municipal authorities and the nongovernmental sector).

In the article are used primary data and secondary sources and the use of both, which is termed triangulation, or dual methodology. Primary data, which we used, is the data collected by us, i.e. interview, observation, questionnaires. Secondary sources used in the article are data that already exists - previous research, official statistics, mass media products, government reports, web information, historical data and information.

\section{RESULTS AND DISCUSSION}

The word „migration“ has a Latin origin of „migratio“, which means resettlement. Today, migration is understood to mean the transfer of people across a certain border (settlement state) for a longer period of time but with a mandatory change of residence for these people for a certain time or permanently. According to Brian Goodal, migration is a permanent or inconsistent change of people's domicile. According to the Geographical Geographical Survey (1994), migrations represent relocations of people from one place to another, crossing a statistically defined border (state, district, settlement, regional, etc.) and changing residence for a certain period or forever. According to IOM, „migration“ is the movement of a person or group of persons, either via an international border or within a single country. This is the movement of the population, covering all types of movement of people, regardless of its duration, composition and reasons. It includes the migration of refugees, displaced persons, economic migrants, as well as persons moving for other purposes, including for the purpose of family reunification [8]. Regarding the concept of „migration“, UNESCO gives the following definition - this is the crossing of the border of a political or administrative unit for a certain minimum period of time. It includes the movement of refugees, displaced persons and economic migrants. Internal migration refers to the transition from one area (province, district or municipality) to another within a single country. International migration is a territorial movement of people between national nations. Two forms of resettlement can be excluded from this broad definition: firstly, a territorial movement that does not lead to a change in community relations and therefore remains largely irrelevant to the individual and to society, such as tourism ; second, relocation in which individuals or groups affected by it are only passive objects and not active traffic agents, such as the organized transfer of refugees from their countries of origin, to a safe place. According to UNESCO, the term „migrant" can be understood as "any person who lives temporarily or permanently in a 
country where he or she is not born and has acquired some significant social connections with that country". However, this definition may be too narrow, as some state policies treat some people as migrants even when he / she is born in the country.

The increasing migratory pressure creates a need to redirect significant financial and organizational resources to address the situation. The lack of prospect of lasting stability in the source countries determines the continuation of this trend, with limited capacity of institutions to secure the processes. In this regard, the expected increase in migrants in our territory creates direct risks for a humanitarian crisis. At the same time, the maintenance of a large number of asylum seekers who have been granted asylum and requiring foreigners requires considerable financial resources, which are not planned and redirected from other spheres that are sensitive to the Bulgarian society. This creates conditions for tension among certain social groups. The increase in persons seeking and receiving protection is causing additional pressure on the social security and healthcare system, which are in a chronic financial deficit. Modern migratory processes and their consequences have rightly become one of the central areas of current policy in the European Union. For centuries, Europe itself has been a continent of emigrants, with the inhabitants of European countries colonizing vast areas of the world, seeking wealth, freedom and peace. Nowadays, the trend is reversed: in the age of globalization, the Old Continent has become the ultimate goal of migratory processes unknown until now, in scale and intensity. The availability of highly educated, skilled and unoccupied work resources is an important factor in reducing finance to prepare and stimulate immigration in a given workforce [5]. The classic "Push-and-Pull" model here is easy to apply here: on the one hand, factors such as poverty, lack of prospects, overcrowding, wars of repression, natural upheaval, etc. motivate residents of underdeveloped or developing countries to emigrate to seek new life elsewhere. On the other hand, Europe suffers from a marked aging population and a lack of skilled workers. These processes call into question the hitherto accepted implications: the welfare state, the welfare and the competitiveness of European economies globally. In order to be able to support them, the EU needs serious human resources, but it can not afford it alone. In this sense, it can be said that the migration processes to the Union, even with a superficial view of the problem, are a non-alternate phenomenon which, to a large extent, is already shaping the future of our continent. In order to be able to capture the role of European policy in this process, and even more so in order to outline its priorities, more in-depth analyzes on this subject are needed because of the scale and complexity of migratory processes geared to Europe. Migration is a topic that is one of the major in the era of globalization, and this makes it a challenge requiring conceptual solutions at all levels, from strategic to local. In this sense, the EU is unlikely to be able to put all aspects of migration under control. It would be more realistic, through moderate control, to derive maximum benefit from it, avoiding its negatives. Migration policies during different historical periods are motivated by relevant political, economic and social circumstances. The worst migratory waves have been caused by world and regional wars. The salvation of human life, family and children has always been at the heart of the evolution of migration phenomena. Migration policy is a relatively new part of the field of migration [1].

To be able to cope with this difficulty, the EU must develop long-term plans that take account of current developments in the Member States. But they are not pink: most European countries are forced to struggle with more drastic demographic declines, although some are subject to lasting waves of migration. It is expected, for example, by 2060, to reduce the population of Germany from 82 to 65 million inhabitants, while 
maintaining the current migration rates for the country. One woman counts 1.6 children, with a minimum of 2.1 for maintaining natural growth. As a comparison, some countries in Africa, which have a doubling rate below 30 years, can be compared. There are 495 million people living in the EU in 2008, with a ratio of 4 to 1 employees this year. In 2060, however, it is expected to drop to 2 in 1 . This puts politicians in a seemingly impossible task: supports the functioning of countries where people are already exhausted. Only by 2020 European economies will need an additional 16 million skilled workers [9]. Yes, for sure, migration is a major part of the solution. But is it the only one? How can we explain the fact that there is mass unemployment in countries with strong migratory flows, although European Member States rely on migrants in the primary (IT experts, doctors, medical staff) and the secondary (servicing professions that citizens of " Old Europe "do not want to perform) labor sectors? A typical example of this is Spain - there has been an increase in the number of migrants by 194\% (up to 4.8 million) over the period 2000-2005, despite the prolonged period of the first decade of the 20th century and dramatically deepened since the beginning of the financial crisis economic recession, the consequences of which are over 4 million unemployed (youth unemployment reaches even 50\%). For the same period in Italy, the number of migrants increased by $54 \%$ to 2.5 million. Former Italian Foreign Minister Franco Frattini will be remembered with his appeal for a solid redistribution of migrants between member states so that his country can rest. A general trend in the EU is for businesses to call for loosening of regulations allowing foreigners to settle in the territory of the Union, while certain political circles as well as the public express concerns about the loss of national identity and jobs. Obviously, migration is ambiguous, even a polarizing and controversial process. Bindings and players involved cover all social strata and interest groups, so an in-depth approach is needed in defining different types of migration. From the point of view of the interests of the EU (and its strategy), it is most reasonable to divide the migrants according to their qualifications to high, medium and unskilled, as well as legal and illegal. Below I will try to outline the policy towards each of these categories. In 2007, there are 18.5 million people in the EU. "third parties". This is $4 \%$ of the total population. However, this does not include those who have already received European citizenship. The three most numerous migrant ethnicities in the EU are the Turks (2.3 million), the Moroccans (1.7 million) and the Albanians ( 0.8 million). A total of 9 million EU citizens use their right to freedom of movement and reside in another Member State. The number of asylum seekers has dropped to 200,000 people - a kind of bottom compared to previous years. The EU's migration balance for 2010 is positive: the settlers are 1.75 million more than the displaced (this method, however, puts refugees and students on the same plane). The number of illegal immigrants in the EU is estimated at 4.5 million, although it is likely to be significantly higher. To this is added the fact that, with the accession of the countries of the former Eastern Bloc in the Union, certain migratory problems with clear social dimensions are formally concealed from the right of free movement, but in practice they are still on the agenda and even deepened. A recent example is the controversy in 2012 about the camps of Bulgarian and Romanian Roma in France, where European mobility and nomadic ways of life collide in an impressive way.

Regarding legal immigration, at a political level, Europe can speak of a generally positive attitude, leading also to a number of concrete initiatives. There are laws that allow immigrants, after working for at least a year, to come together with their families. Persons who have been legally resident for five years in the EU may be granted a long-stay permit, which allows them to pass on a higher level of qualification or to work in another Member 
State of the Union. Other regulatory acts concern the introduction of pan-European reception criteria for students and researchers. Particular attention is paid to the so-called a "blue card", which is an accelerated procedure for admission to the labor market of a particular Member State of highly qualified professionals on particularly favorable conditions of stay, including the granting of a work permit throughout the EU after a period of two years. In a more interconnected, globalized world, new concepts are emerging as an alternative to past migratory phenomena. Among them, it is worth mentioning "circulating migration" (stay of foreign labor for a certain time, then return to the country of origin and application of the acquired competencies and knowledge there), the concept of "social transfers" (transfer of Western values and working culture in the home country of migrants), and "brain circulation" instead of the traditional "brain drain". Account is also taken of the option, with a view to the integration process, to interact more closely with the immigrant networks established in the host countries, which until recently were considered dangerous and formed parallel cultural societies. On the other hand, the EU has set itself the priority task of countering illegal immigration. Every year 500000 illegal immigrants are arrested on European territory; of them, on average, 40\% are returned to their home countries, another 300000 are stopped at the border. This priority is also of particular importance given that illegal immigration and international organized crime interact, which directly affects European security. The EU pursues this goal with internal (strict sanctions against employers who appoint illegal immigrants, some Member States undertake to strengthen their labor control) and external measures. The instruments available to the Union are the European External Borders Fund, the European Return Fund and the European Agency for the Management of Operational Cooperation in the Peripheral Regions or, in short, Frontex. The latter is involved in carrying out joint operations (currently 25) on land and sea borders, as well as at EU airports, to prevent illegal immigrants from reaching European territory.

Despite the undeniable positive effects of immigration into the EU, such as:

- Fusion of fresh labor, satisfying hunger in the labor market;

- Increasing birth rates and improving demographics;

- Increasing EU innovation, research and development through skilled immigration workers;

- Multiculturalism and globalization and many others,

there are also aspects of immigration, which are unfortunately negative for the EU and affect the security and sense of security of its citizens.

Due to the economic crisis, the situation of immigrants in Europe at this time is particularly difficult. One of the most frequent reasons for immigration is the demand for employment, but as employers usually dismiss first employees and workers, the most severe consequences of the economic downturn are felt by immigrants, especially in the countries hardest hit by the crisis [10]. If this trend continues, the integration of this population in the long run will be further hampered. Whether its important contribution to the development of the economy during periods of boom and turbulence, immigrants are increasingly identified as a burden or as undesirable competition for the local population to compete for the few jobs available (although the research convincingly suggests that the effect of such a competition on employment levels of the local labor force is negligible). All this continues to fuel prejudice against immigrants, which in turn increases the discrimination against them [7]. 
Despite all the risks to immigrants, in particular the economic crisis, which created negative prerequisites for employment, Eurostat statistics inform us that asylum seekers of the 28 EU Member States have increased significantly over the past year.

According to CNN's published statistics by Frontex [6], the main routes through which immigrants reach the territory of the European Union are the eastern Mediterranean (Spain), the western Mediterranean (Greece and Bulgaria), the Central Mediterranean (Italy), Apulia and Calabria, the western Balkans (Serbia), the eastern border (Ukraine) Circular Route (Albania - Greece). These roads are under constant threat from illegal immigrants from different countries.

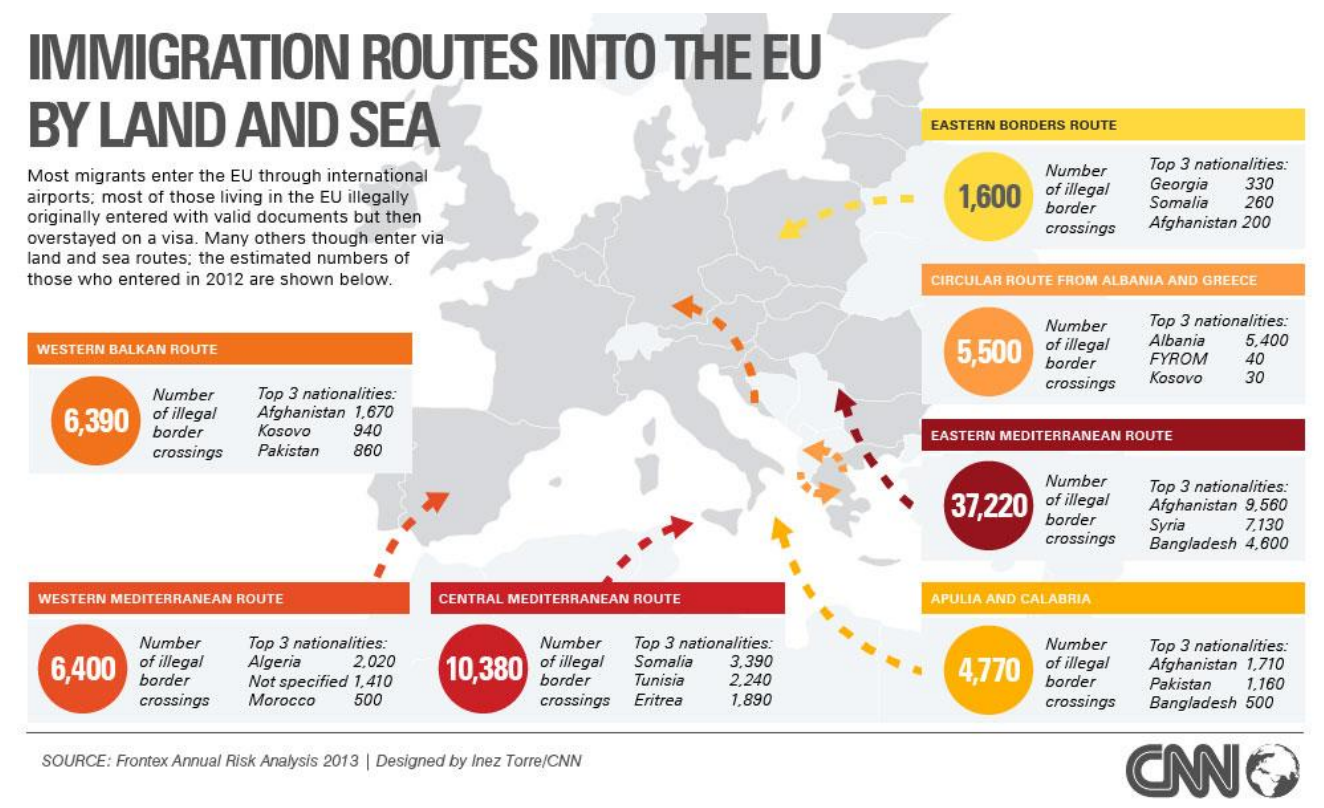

Figure 1. Immigration routes into the EU by land and sea

The European Union is developing a wide range of policies and instruments to tackle the growing challenge of migration, the security of external borders and asylum. It does so in full respect of human rights and fundamental values. EU actions complement the powers and actions of the Member States, which, in many cases (for example, in the field of residence permits, asylum decisions, refugee admission, external border management, etc.) retain their exclusive competence. Migration, however, also requires effective governance to address challenges such as "brain drain" (emigration of educated people), the exploitation of migrants and the consequences of migration for urbanization. Migration, however, affects not only the number but also the composition of the population. The displacement of large masses of young people from the villages aggravates the age structure of the rural population and improves the age structure of the urban population. Migration of young people from these settlements leads to reduced economic potential and worsening demographic potential [3]. Concerning education, the negative tendencies are manifested by the fact that many young people with higher education go abroad and the number of illiterate persons is increasing. In addition to the aging process differences are predetermined and from the migrations of young people with higher education to the cities where they can find better conditions for personal and professional development [4]. 


\section{CONCLUSION}

Migrations are definitely complex processes for which some of the major organizations dealing with their problems, such as UNESCO, the UN, and so on, have chosen definitions and classifications. It can not be unambiguously concluded that they only bring benefits or only harm to societies. They achieve multicultural diversity, innovation, opportunities for development. Numerous programs, strategies, normative documents and frequent debates on the issue of increased migration processes in the European Union indicate the seriousness of the problem. The timeliness of the topic suggests that the real effects of immigration in the European Union and the development of new methods and tools to deal with the negative aspects of this process are yet to be clarified.

\section{REFERENCES}

[1] Ivanov M., Kl. Naydenov, MIGRATION AND DEMOGRAPHIC CHALLENGES FOR BULGARIA, 5th SGEM International Multidisciplinary Scientific Conferences on SOCIAL SCIENCES and ARTS SGEM2018, 2018, doi:10.5593/sgemsocial2018/4.1/S18.045

[2] Naydenov Kl., INTERNATIONAL MIGRATION IN EUROPE IN THE 21ST CENTURY, GEOBALCANICA Proceedings, 2018, p. 191-197, ISSN 18577636

[3] Naydenov Kl., T. Traykov, DEMOGRAPHIC SITUATION IN URBAN AREAS OF REPUBLIC OF BULGARIA IN THE LAST 25 YEARS, 1st International Scientific Conference Geobalcanica , 2015, DOI: http://dx.doi.org/10.18509/GBP.2015.27 UDC: 314.911.375(497.2) „1990-2015““

[4] Traykov T., Naydenov Kl., DEMOGRAPHIC SITUATION IN RURAL AREAS OF REPUBLIC OF BULGARIA IN 21 CENTURY, 1st International Scientific Conference Geobalcanica , 2015, DOI: http://dx.doi.org/10.18509/GBP.2015.26 UDC: 314:911.272(497.2),,21vek“

[5] Найденов Кл., М. Иванов, Управление на демографския риск в Р България - тенденции и перспективи, Годишник на МГУ “Св. Иван Рилски”, том 59, Annual of the University of mining and geology „St. Ivan Rilski“, Vol. 59, Part IV, Humanitarian sciences and Economics, 2016

[6] http://frontex.europa.eu/trends-and-routes/migratory-routes-map

[7] http://www.coe.int/t/policy-planning/GEP/translations/Report_GEP_Bulgarian.pdf

[8]http://www.iom.int/cms/en/sites/iom/home/about-migration/key-migration-terms1.html\#Migration

[9]Naydenov Kl., THE DEMOGRAPHIC DEFICIT IN THE ECONOMIC DEVELOPMENT OF THE REPUBLIC OF BULGARIA - CONSEQUENCES AND DECISIONS, 4th international scientific conference on Social Science \& Arts SGEM 2017, 2017

[10]Naydenov Kl., Regional image - a prerequisite for economic development, ANNUAL OF THE UNIVERSITY OF MINING AND GEOLOGY "ST. IVAN RILSKI", Humanitarian sciences and Economics, 60, 2017 